\title{
Electre Yöntemi ile Otomotiv Sektöründe Tedarikçi Seçimi: Yeşil Tedarikçi Seçimi Uygulaması
}

\author{
Hikmet Erbıy1k $^{1^{*}}$, Gizem Alkan Kabakçı ${ }^{2}$, Ayşenur Erdil ${ }^{3}$ \\ 1*Yalova Üniversitesi, Mühendislik Fakültesi, Endüstri Mühendisliği Bölümü, Yalova, Türkiye, (ORCID: 0000-0002-1997-4628), hikmeterbiyik53@ gmail.com \\ ${ }^{2}$ Yalova Üniversitesi, Mühendislik Fakültesi, Ulaştırma Mühendisliği Bölümü, Yüksek Lisans Öğrencisi,Yalova, Türkiye (ORCID: 0000-0002-3676-0760), \\ gizem.alkan@renault.com \\ 3ísatanbul Medeniyet Üniversitesi, Siyasal Bilgiler Fakültesi, İşletme Bölümü, İstanbul, Türkiye (ORCID: 0000-0002-6413-7482), runesyalidre61@ gmail.com
}

(2nd International Conference on Access to Recent Advances in Engineering and Digitalization (ARACONF)-10-12 March 2021)

(DOI: 10.31590/ejosat.903952)

ATIF/REFERENCE: Erbıyık, H., Alkan Kabakçı, G. \& Erdil, A. (2021). Tedarikçi Seçimi Uygulaması. Avrupa Bilim ve Teknoloji Dergisi, (24), 421-429

\section{Öz}

Bu çalışmada otomotiv sektöründe faaliyet gösteren 3 tedarikçinin yapılan performans değerlendirme sonuçları incelenmiştir. Her bir tedarikçi 5 farklı ana kriterde incelenmiş ve değerlendirilmiştir. Bu kriterler; kalite yeterlilikleri, mühendislik yetkinlikleri, yeşil lojistik yönetimi, maliyet performansları ve yönetim stratejileri olarak belirlenmiştir. Yeşil lojistik yönetimi değerlendirme sonuçları için çalışma da 5 anket sorusu paylaşılmıştır. Bu anket sonuçları 1şığında tedarikçilerin yeşil tedarikçi ve yeşil tedarik zinciri prensiplerine uyumları sınanmıştır ve uzman görüşleri olarak tedarikçi seçim çalışmasına dahil edilmiştir. Kalite yeterlilikleri, mühendislik yetkinlikleri, yeşil lojistik yönetimi, maliyet performansları ve yönetim stratejileri olarak belirlenen farklı uzman görüşleri alınmıştır. Bu uzman görüşleri dikkate alınarak kriterlere SWARA kriter ağırlık analizi uygulanmıştır. Tedarik seçimi yöntemi olarak Electre yöntemi seçilmiştir. Sonuçlar değerlendirilmiştir.

Anahtar Kelimeler: Tedarikçi seçimi, yeşil tedarikçi seçimi, Electre yöntemi, SWARA kriter ağırlık analizi, performans değerlendirme

\section{Supplier Selection in the Automotive Sector with the Electre Method: An Application for Green Supplier Selection}

\begin{abstract}
In this study; the performance evaluation results of suppliers that are active in automotive sector were examined. Each supplier has been examined and evaluated on different 5 main criteria. These criteriasarequality competencies, engineering competencies, green logistic management, cost performance and management strategies. For the green logistic management evaluation results 5 question were addressed in survey. Different expert opinions were taken into considerations which were determined as quality competencies, engineering competencies, green logistic management, cost performance and management strategies. SWARA criteria weighted assessment was applied in order to weight each criterion. Electre methodology has been chosen as the supplier selection method.
\end{abstract}

Keywords: Supplier selection, green supplier selection, Electre methodology, SWARA criteria weighted assessment, performance evaluation.

\footnotetext{
*Sorumlu Yazar: hikmeterbiyik53@gmail.com
} 


\section{Giriş}

Günümüzün hızla değişen, git gide zorlaşan hayat ve çalışma koşulları, insanları, kurum, kuruluş ya da işletmeleri sürekli olarak "iyi" ve "başarılı" karar vermeye itmektedir. Ayakta kalabilmek, rekabet avantaj1 kazanmak ve bunu sürdürmek için sağlıklı karar verme bir gereklilik olmaktadır. Kişilerin, yöneticilerin, kurum, kuruluş ya da işletmelerin en temel görevleri farklı konularda kararlar vermektir. Geleneksel olarak bir karara ulaşılırken, karar süreci ile ilgili veriler toplanır ve sezgisel olarak o anki koşullar ve faktörler dikkate alınıp analiz edilerek sonuca varılır. Ancak artık birçok durumda başarılı kararlar verebilmek için alternatif davranış yolları bilimsel karar verme tekniklerinin desteği ile değerlendirilmektedir.

Karar vericiye bu tür problemlerin üstesinden gelmede onun kişisel değer yargılarından da faydalanarak- yardımcı olan bilimsel teoriler ve analitik yöntemler geliştirilmiştir. Daha önceki dönemlerde kararlar; tecrübelere, sezgilere ve sınırlı bilgilere dayandırılarak verilirdi. Fakat zaman içerisinde artan rekabet, maliyet ve ilişskilerin karmaşıklaşması vb. nedenlerden dolayı rasyonel karar almak için tecrübeler, sezgiler, ve sınırlı bilgilerin yanı sıra karar sürecinin analitik olarak da değerlendirilmesi gerekir. Modern ve analitik karar destek yöntemlerini kullanan organizasyonlar, giderek kompleks bir hal alan iş ortamında önemli bir rekabet avantajı kazanmaktadırlar. Yönetim bilimi literatüründe son y1llarda giderek artan bir ilgi ile Çok Kriterli Karar Verme (ÇKKV) alanı, bir karar durumu ile ilgili olarak birbiri ile çatışan birden fazla kriteri uzlaştıran mümkün olan "en iyi /uygun" çözüme ulaşmaya çalışan yaklaşım ve yöntemlerin bütünüdür.Genel olarak kara vermede sürecin aşamaları;

-Amaç belirleme ve sorunun tanımlanması,

-Amaç ve sorunları irdeleme, öncelik belirleme,

-Alternatif belirleme,

-Alternatifleri belirleme,

-Alternatifleri irdeleme ve değerlendirme,

-Seçim kriterlerini belirleme ve seçim yapma şeklinde siralanabilir.

Karar, mevcut en az iki alternatif arasından seçim yapılmasıdır. Herhangi bir karar eylemi için gerekli olan elemanlar aşağıdaki gibidir.

1. Karar Verici: Mevcut seçenekler arasından seçim yapan kişi yada grup

2. Amaç: Karar verici ve vericilerin faaliyetleri ile ulaşılacak amaçlardır.

3. Karar Kriterleri: Karar verici/ vericilerin seçimini oluşturmada kullanacağı değerler sistemidir.

4. Seçenekler: Karar verici/ vericilerin seçebileceği alternatifler olup, kontrol edilebilir değişkenlerdir.

5. Olaylar: Kontrol edilemeyen değişkenler olup, karar verici/ vericilerin seçimlerini etkileyen çevre şartlarıdır.

6. Sonuç: Her bir seçenek ve olaydan ortaya çıkan değeri yansitir.
Bu çalışma; bir ÇKKV problemi olarak ele alınmış bir tedarikçi seçim sürecini anlatmaktadır. Literatürde sıkça kullanılan yöntemlerden bir olarak tedarikçi seçim probleminin analizinde Electre yöntemi kullanılmıştır. Beş farklı uzman görüşü dikkate alınarak 3 farklı tedarikçinin performans değerlendirme sonuçları alınmıştır. Bu uzman görüşleri 3 farklı tedarikçi için 5 farklı ana kriterde değerlendirilmiştir. Uzman görüşleri alınırken anket metoduna başvurulmuştur. $\mathrm{Bu}$ ana kriterler; kalite, mühendislik yetkinlikleri, yeşil lojistik, maliyet ve yönetim olarak dikkate alınmıştır. Makalede özellikle yeşil lojistik anket soruları ve değerlendirme metodolojisi detaylandırılmıştır. Günümüzde oldukça dikkat çeken ve giderek önemi anlaşılan bir konu olarak yeşil tedarikçi seçimine bir örnek olması açısından bu anket detayının iredelenmesi oldukça yararlı bir noktaya parmak basacaktır. Her bir kriter kendi içerisinde uzman değerlendirmeleri ışı̆̆ında SWARA metodu ile ağırlıklandırılmış ve Electre yöntemi için girdi oluşturmuştur.

\section{Literatür Taraması}

Ertuğrul ve Karakaşoğlu (2011) yılında; bir işletme için dizüstü bilgisayar seçimi probleminde ELECTRE ve Bulanık AHP Yöntemlerini kullanmıştır. İşletmelerde karar vermeye yardımcı olmak için ELECTRE ve Bulanık AHP yöntemlerine göre bilgisayar seçimi yapılmak istendiğinde önem derecesine göre marka güvenilirliği, işlemci hızı, fiyat, sistem belleği, ekran kartı, ağırlık, pil ömrü ve sabit disk kapasitesi önceliklerine göre tercih yapılmasının daha uygun olacağı görülmüştür.

Atıcı ve Ulucan (2009) yılında yaptıkları araştırmada; Türkiye enerji sektörü kapsamında karar analizi yöntemlerinin kullanılmasına yönelik iki adet uygulama yapmıştır. Birinciuygulama, çeşitli hidroelektrik santral projelerinin değerlendirilmesine yönelik çalışmadır. İkinci uygulama da seçilen rüzgar santrali projeleri değerlendirilmesine yöneliktir. Projeler çeşitli kriterlere bağlı olarak ELECTRE ve PROMETHEE çok kriterli karar verme yöntemlerini uygulayarak sıralanmaktadır.

Eryürek ve Tanyaş (2003) y1lında, basit toplamlı ağırlıklandırma ve ELECTRE yöntemleri kullanılarak hata analizi tanımlamışlardır ve hata analizinin karar verme bölümü daha objektif hale getirilmiştir.

Karacasu, (2006) yılında yaptığı çalışmasında, kent içi toplu taşıma yatırımlarının değerlendirilmesinde karar destek modelinde ELECTRE ulaştırma yatırımlarının değerlendirilmesi için karar destek modelini ELECTRE yöntemi ile oluşturmuş ve sonuçlar ortaya konulmuştur. Çıkan sonuçlara göre kullanıcılar ve işletmeciler özel halk otobüslerini, uzmanlar ise kamu otobüslerini tercih etmişlerdir.

Soner ve Önüt, (2006) yılında yaptıkları araştırmada, nitel ve nicel kriterleri dikkate alarak en uygun tedarikçinin seçimi amaçlamıştır. Tedarikçileri değerlendirmesinde iş kapsamındaki iş masrafları, ortalama firsat maliyetleri, mesafe, uzaklık, ömür, hayat döngüsü, teknoloji odaklılık, teknoloji kullanımı, hız, verimlilik, kalite gibi kriterlerin öncelikli olduğu tespit edilmiştir. 
Yürekli, (2008) y1lında taarruz helikopterleri seçiminde ELECTRE yöntemini kullanmıştır. Çalışmada belirlenen kriterlere göre 6 ayrı alternatif arasından, Türk Silahlı Kuvvetlerinin ihtiyacını karşılayacak en uygun taarruz helikopterinin bu metotla seçilmiştir (Yürekli, 2008; Akyüz ve Soba, 2013).

Çağıl (2008) yılında yaptığı çalışmasında, Türk Bankacılık Sektöründe 2006-2010 dönemlerine ait kamu ve özel sermayeli mevduat bankaları ile Türkiye'de kurulan yabancı sermayeli bankalarda finansal performans analizini her bir y1l için ELECTRE yöntemi kullanarak yapmayı hedeflemiştir. Bankaların performanslarının sıralaması değerlendirildiğinde ise kriz dönemlerinde bazı bankalar için sıralama sapması yaşandığı saptanmıştır.

Bai ve Sarkis (2010) yılında üç ana nitelik arasındaki ilişkiyi incelemek amacıyla bir çalışma yapmıştır. Kurumsal nitelik, tedarikçi geliştirme programlarının niteliği ve performans çıktıları gibi üç ana ilişkiyi incelemek için sıkı küme teorisini kullanmışlardır.

Blome ve diğerleri (2014) yılında yeşil tedarikçi geliştirme sonuçları olarak üst yönetim desteği ve firma performansı değerlendirmesinde karşıt görüşleri beraber değerlendirmişlerdir. Dou ve diğerleri (2014) yılında yaptıkları araştırmada, bulanık AHP yöntemi ile Çin'de sulama ekipmanları sektöründe lider konumunda bulunan bir işletme olarak tedarikçilerinin çevresel performanslarının gelişmesine etki sağlayacak programları belirlemişlerdir.

Fu ve diğerleri (2007) yılında yeşil tedarikçi geliştirme programlarını değerlendirmek amacıyla telekomünikasyon hizmet sağlayıcılarına gri tabanlı DEMATEL yöntemini uygulamışlardır.

Tunçel, Belbağ ve Çimen (2017) yılında yaptıkları çalışmada, otomobil markalarının çeşitli satın alma kriterlerine bağlı olarak sıralanmasını yapabilmek için bulanık mantık içeren ÇKKV yöntemlerinden Bulanık ELECTRE I yöntemini kullanmıştır. Sonuçların karşılaştırılmasına yönelik markalarınsıralaması, geleneksel ağırlıklı ortalama yöntemi uygulanarak da elde edilmiştir. $\mathrm{Bu}$ çalışmanın temel amacı geleneksel ağırlıklı ortalama sıralaması ile yapılmış sıralama ile Bulanık ELECTRE yöntemi ile yapılmış sıralamanın karşılaştırılmasıdır.

Wang ve diğerlerinin yaptıkları çalışma (2020) kapsamındaki ampirik-deneye dayalı sonuçlar, dahili KSS'nin (kurumsal sosyal sorumluluk)(çalışanlara yönelik yönetim uygulaması) ve dış KSS'nin (dış paydaşlara yönelik yönetim uygulaması) yeşil tedarik zinciri yönetimi üzerinde olumlu bir etkiye sahip olduğunu göstermiştir. Yeşil tedarik zinciri yönetimi (YTZY), işletme performansı üzerinde olumlu bir etkiye sahip olduğu ve büyük veri analitiği yeteneği, dış KSS ile yeşil tedarik zinciri yönetimi arasındaki ilişki üzerinde olumlu etkiye sahip olduğu gözlemlenmiştir. Çalışma da teorik katkılar ve pratik çıkarımlar da tartışılmıştır.

RezaHoseini ve diğerlerinin makale çalışmasında, önerilen yeşil tedarik zincirinde tedarikçi seçimi ile proje planlama ve çizelgeleme arasındaki sinerjiyi tartışılmıştır. Çalışmada ayrıca inşaat sektöründe gerçek bir operasyonel zorluk haline gelen

e-ISSN: 2148-2683 tedarikçi seçiminin dengelenmesi, filo tipinin seçilmesi ve proje zaman planlaması konuları da proje gecikmelerini en aza indirerek lojistik maliyetler ve sera gazlarının yayılması da en aza indirilebildiğini belirtilmiştir. Ayrıca, sonuçları daha gerçekçi hale getirmek için üretim kapasitesi ve maliyetleri, karamsar, normal ve iyimser olmak üzere üç ekonomik koşul altında belirsiz (bulanık-olasılıklı) bir ortamda değerlendirilmiştir.

Lamba ve Thareja (2020)' nin çalışmasında, YTZY 'nin yavaş uygulanmasından sorumlu olan engeller, sorunlar tartışılmıştır. Ayrıca, TOPSIS yönteminin yardımı ile bu engelleri doğrulamak ve sıralamak için bir girişimde bulunulmuştur. Çalışmada, Hindistan bağlamında YTZY 'nin yavaş uygulanmasına neden olan en çok etkilenen engelin hükümet politikaları ve düzenlemeleri olduğu sonucuna varılmıştır.

Mojumder ve Singh (2021) çalışmasında, literatürde yeşil tedarik zinciri uygulamalarının benimsenmesi için çeşitli itici güçler, kolaylaştırıcılar ve engeller rapor edilmiştir. Bu yöndeki gerçekler ışığında, mevcut araştırma çalışmasının temel amacı, yeşil tedarik zinciri uygulamalarının çeşitli kategorilerdeki Hint inşaat şirketleri tarafından uyarlanabilirliğini araştırmak ve ardından ölçütlerin, kolaylaştıııcıların ve engellerin inşaat endüstrisinin hazırlığı ile ilişkisini belirlemek olmuştur. Çalışmada, Analitik Hiyerarşi Süreci (AHS) yöntemini kullanılarak önceliklendirme yapılmıştır. Değerlendirme ölçütlerinin, etkinleştiricilerin ve engellerin öncelikli yapısı da AHS yöntemini kullanılarak geliştirilmiştir. Sonuçlar kurumsal teorinin, karmaşıklık teorisinin, ekolojik modernizasyon teorisinin, kaynak temelli görüşün ve kaynak bağımlılığı teorisinin olumlu yönde desteklendiğini göstermiştir.

\section{Tedarikçi Seçimi}

\subsection{Tedarikçi Seçiminde Yöntemler}

Günümüzde tedarikçi seçimi başarılı projelerin ve başarılı satın alma süreçlerinin temeli olarak kabul edilmektedir. Doğru karar verilmiş bir tedarikçi seçimi ile şirketler pazarda kendilerinemaksimum rekabetçilik ve kazanç minimum kalitesizlik ve maliyet üstünlüğü kazandırmaktadır.

Kalite, maliyet, transfer, garanti, teknik özellikler ve fiyat gibi faktörler tedarikçi performansını birebir etkilemektedir. Açıklamada belirtildiği üzere tedarikçi seçimi, aralarında çelişki bulunan, sayılabilen ve değerlendirilebilen faktörler ve sayılamayan ve değerlendirilemeyen faktörlerin denge içerisinde olmasını amaçlayan çok ölçütlü bir karar problemi olarak tanımlanabilir. Sürekli yenilenen rekabet koşulları ve gelişimine devam eden pazar ve teknolojiyle birlikte seçim yapılacak olan tedarikçi sayısında artış görülmektedir. Bu durum seçim işlemini zorlaştırmaktadır. Firmalar belirledikleri ölçütlere göre tedarikçilerin performans verilerini oluşturmaktadır ve bu verileri dikkate alarak karar modelleri yardımıyla değerlendirme yapmaktadır. Amaç birçok ölçütü aynı anda maksimum seviyede karşılayabilen tedarikçiyi bulabilmektir. Temelde iki farklı tedarikçi seçim problemine rastlanılmaktadır.

Tedarikçi seçimi, genel olarak iki gruba ayrılabilir. Bunlar çalışılan tedarikçi durumuna göre tek ve çok kaynaklı 423 
tedarikçiyle çalışma olarak ifade edilebilir. İşletmeler belirli dönemlerde ve durumlarda tedarikçileriyle uzun süreli anlaşmalar yaparak sürekli aynı tedarikçiyle çalışmayı tercih edebilir. İşte yapılan bu tarz çalışma tek kaynaklı çalışma olarak tanımlanabilir.

Tek bir tedarikçiyle çalışmanın avantajları şu şekilde siralanabilir;

- Uzun süreli ve yüksek hacimde devam eden ilişkilerin müşteri ile tedarikçi arasındaki bağı ve ilişkiyi güçlendirmesi,

- Aynı sorumluluk ve teyitleri tüm ürün partilerinde sağlanıyor olması,

- Malzeme farklılığının azalması,

- Satın alma hacmi arttığı durumlarda indirim imkanının ortaya çıkması

- Müşteri ve tedarikçi arasındaki uzun soluklu ilişkinin iletişimi hızlı ve verimli hale getirmesi.

Birden fazla tedarikçi ile çalışmanın avantajları şu şekilde siralanabilir;

- Piyasayı daha iyi analiz etmek ve rekabetçilikten maksimum düzeyde yararlanabilmek

- Tedarikçiler arasındaki rekabetten faydalanarak fiyat avantajı sağlamak,

- $\quad$ Sadece tek bir tedarikçiye bağımlı olmamak ve olumsuz bir durumda diğer tedarikçi ile iletişime geçebilmeye imkân sağlamak,

- Birden çok miktarda ve farklılıkta talebe minimum sürede yanıt verebilme imkânı sağlamak.

Literatürde tedarikçi seçimi problemlerinde aktif olarak kullanılabilen birçok ÇKKV yöntemi bulunmaktadır (Zeger. Et al., 1999; Luitzen ve Eva, 2001 ve tedarik zinciri seçim odaklı literatürden derlenmiştir) Bunlardan bazıları;

(i) Analitik Hiyerarşi Süreci (AHS); Tüm kriterler ile göreceli önem derecelerinin belirlenmesinde karar vericinin görüşlerine ihtiyaç duyan bir tekniktir.

(ii) Analitik Ă̆ Süreci (AAS); AHS 'nin geliştirilmiş halidir. Bu gelişim AHS 'nin hiyerarşik yapılanma gerekliliğinden kurtulmak amaçlı yapılmıştır.

(iii) VIKOR (VIse Kriterijumsa Optimizacija I Kompromisno Resenje) Yöntemi; Alternatifleri arasından birden fazla sayıda ve aynı anda uygulanabilen kriterlere bağlı olarak en iyi tercihin seçilmesine imkân sağlayan araçtır.

(iv) TOPSIS (TechniqueforOrderPreference by SimilaritytoIdeal Solutions) Yöntemi; Alternatifler arasından en iyi seçimin yapılmasına imkan sağlayan tekniktir. Optimal alternatife olan uzaklığın değerlendirilmesi mantığı üzerine kuruludur.

(v)ELECTRE (Elimination and Choice Translating Reality) Yöntemi; Kriterler için alternatifler arasındaki ikili üstünlük karşılaştırmalarına dayanmaktadır.

(vi) PROMETHEE (Preference Ranking Organization METHod fo rEnrichment of Evaluations) Yöntemi; Mevcut ÇKKV yöntemlerinin uygulamadaki zorluklarından yola çıkarak ortaya atılmış bir önceliklendirme yöntemidir.

(vii) Veri Zarflama Analizi; Benzer yapıdaki karar verme birimlerinin göreli etkinliklerini ölçmeyi amaçlayan doğrusal programlama tabanlı parametrik olmayan bir ölçme yöntemidir.

e-ISSN: 2148-2683 (viii) Gri İlişkisel Analiz; Karar analizlerinde belirsizliğin sayısallaştırılmasında kullanılan alternatif yöntemdir.

(ix) MOORA (Multi-Objective Optimization By Ratio Analysis) Yöntemi; Ayrık alternatiflerle çok amaçlı optimizasyon için önerilmiştir.

(x) MACBETH (Measuring Attractiveness by a Categorica lBased Evaluation Technique) Yöntemi; Karar vericilerin kalitatif yargılardan yola çıkarak bir kantitatif karar verme tekniği oluşturma amacıyla ortaya çıkmıştır.

(xi) UTA (UTilitès Additives) Yöntemi; Karar vericinin tercihleri ile uyumlu optimal fayda fonksiyonları elde etmek için lineer programlama yöntemlerini kullanmaktadır.

(xii) STEM (Step Method) Yöntemi; Karar vericinin amaç fonksiyonlarının göreli önem dereceleri hakkında yeterli bilgiye sahip olmadığı durumlarda kolayca kullanılabilmektedir.

(xiii) PAPRIKA (Potentially All Pairwise Rankings of All Possible Alternatives) Yöntemi; Kriterlere ve özniteliklere göre belirlenmiş ağırlık değerleri hesaplanarak, derecelendirme, alternatifler arasında seçim yapma ya da önceliklendirme konusundaki karar problemlerinin çözümünde kullanılır.

\subsection{Yeşil Tedarikçi Seçimi Değerlendirme ve Yöntemler}

Yeşil Tedarik Zinciri yönetimi sayesinde kaynak kullanımında tasarruf, nihai ürünlerde değer artışı, geri dönüşüm ile enerji tasarrufu gibi kazanımların elde edilebileceği araştırmacılar tarafından savunulmaktadır. Rekabet ortamının sürekli olarak artması, işletmeleri kendilerine en çok fayda sağlayacak tedarikçiler ile çalışmaya zorlamaktadır. Tedarikçilerin veya işletme içi bazı üretim seçeneklerinin değiştirilmesi gibi seçeneklerin yanında tedarikçi performansınıngeliştirilmesi gibi farklı alternatif yöntemler de değerlendirilmektedir. Tedarikçi geliştirme, işletmeye fayda sağlayacak tedarikçileri tanımlamak, sisteme daha iyi entegre etmek, etkinliklerini artırmak ve geliştirmek için harcanan çabaları ortaya koymaktadır. Bu sayede düşük maliyet, güvenilir ve hızlı teslimat, müşteri memnuniyeti, yüksek kalite, esneklik, kaliteli hizmet, kısa ürün hayat çevrimi, operasyonlarda verimlilik gibi performans temelli bazı yararlar elde edilebilmektedir.

Son yıllarda yüksek kalitede hizmet verebilmek, çevresel standartlara uyum sağlayabilmek ve yeşil performanslarını artırabilmek maksadıyla işletmeler tedarikçi geliştirme programlarını uygulamaktadırlar. Literatürde ise yeşil tedarikçi geliştirme üzerine yapılan ve işletmelere yardımcı olabilecek nitelikte çalışmaların sınırlı sayıda olduğu görülmektedir. Literatürde sıkça kullanılan yeşil tedarikçi değerlendirme kriterleri aşağıdaki tabloda özetlenmiştir.

Tablo 1: Yeşil Tedarikçi Değerlendirme Kriterleri

\begin{tabular}{|l|l|}
\hline Yazarlar & Kriter \\
\hline Humpreys ve diğerleri (2003) & $\begin{array}{l}\text { Çevre kirliliği, Üst yönetim } \\
\text { desteği, Yeşil imaj, Çevresel } \\
\text { yetkinlikler }\end{array}$ \\
\hline Curkovic ve diğerleri (2005) & Çevresel ölçütler, ISO \\
Christian (2007). & $14000, \quad$ Çevresel \\
& yetkinlikler,Çevresel \\
& Planlama, çevresel yönetim \\
& sistemi, Çevresel \\
& performans \\
\hline
\end{tabular}




\begin{tabular}{|c|c|}
\hline Büyüközkan ve Çiftçi (2012) & 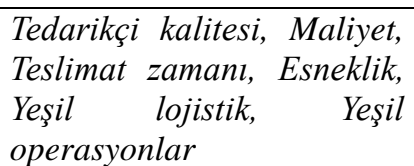 \\
\hline Shen ve diğerleri (2013) & 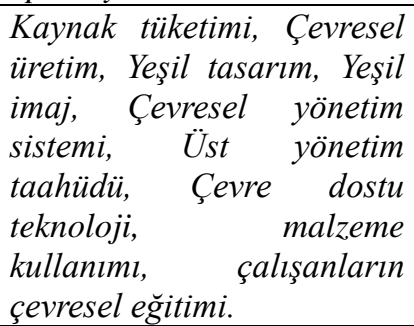 \\
\hline Govindan ve diğerleri (2014) & $\begin{array}{lrr}\text { Yeşil Tedarik } & \text { Zinciri, } \\
\text { Analitik Hiyerarşi Süreci, } & \text { Ḧ̈lçtler, } \\
\text { Değerlendirme } & \text { Ölaynak } \\
\text { Yeşil üretim, } & \text { Kaynallanım }\end{array}$ \\
\hline Wang ve diğerleri (2020) & 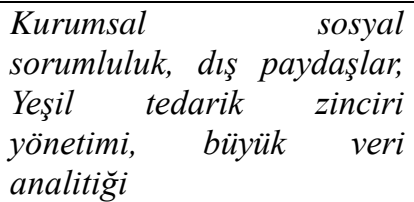 \\
\hline Lamba ve Thareja (2020) & $\begin{array}{l}\text { Yeşil tedarik zinciri } \\
\text { yönetimi, TOPSIS yöntemi, } \\
\text { hükümet politikalarl ve } \\
\text { düzenlemeleri }\end{array}$ \\
\hline Mojumder ve Singh (2021) & $\begin{array}{l}\text { Yeşil Tedarik Zinciri } \\
\text { etkenleri ve engelleri, AHP } \\
\text { metodolojisi kullanllarak } \\
\text { önceliklendirme, } \\
\text { değerlendirme kriterleri, } \\
\text { inşaat sektörü }\end{array}$ \\
\hline RezaHoseini ve diğerleri (2021) & $\begin{array}{l}\text { Yeşiltedarik zinciri, } \\
\text { tedarikçi seçimi ile proje } \\
\text { planlama ve çizelgeleme } \\
\text { arasındaki sinerji, tedarikçi } \\
\text { seçimin dengelenmesi, filo } \\
\text { tipinin seçilmesi ve proje } \\
\text { zaman planlamast, proje } \\
\text { gecikmelerir lojistik } \\
\text { maliyetler, sera gazlarının } \\
\text { yayllması }\end{array}$ \\
\hline
\end{tabular}

Zaidve diğerlerinin 2018'de yaptıkları çalışma, yeşil insan kaynakları yönetimi paketi uygulamaları ile yeşil tedarik zinciri yönetimi (yani harici ve dahili uygulamalar) arasındaki bağlantıyı ve bunların üç alt sürdürülebilirlik performansı (yani çevresel, sosyal ve ekonomik performans) üzerindeki etkilerini incelemeyi amaçlamıştır. Filistin'de en kirletici üretim sektörlerinde (yani gıda, kimya ve ilaç sektörlerinde) faaliyet gösteren 121 firmanın katıldığı özelleştirilmiş bir anketten verilerin toplandığı nicel bir yöntem uygulanmıştır.

Li ve Huang (2017) yaptıkları araştırmada, ilişkisel bağ potansiyel bir moderatör olarak belirlemeye çalışmakta ve yeşil tedarik zinciri uygulamaları, ilişkisel bağ ve yeşil inovasyon performansı arasındaki ilişkileri incelemiştir. Sonuçlar, yeşil tedarik zinciri uygulamalarının ve ilişkisel bağın, yeşil inovasyon performansıyla olumlu bir şekilde ilişkili olduğunu göstermiştir. İlişkisel bağ, yeşil tedarik zinciri uygulamaları ile yeşil inovasyon performansı arasındaki ilişkiyi yönetir. $\mathrm{Bu}$ çalışma kapsamında, ilişkisel pazarlama literatürü ile yeşil yönetim literatürünü bütünleştirerek literatüre katkı sağlamıştır. $\mathrm{Bu}$ çalışma, aynı zamanda, yeşil tedarik zinciri yönetiminde ilişkisel bağın temel rolü için pratik çıkarımlara olanak sağlamıştır.

Liu ve diğerlerinin yaptıkları çalışmada (2020), Sürdürülebilir bir Yeşil kapalı döngü tedarik zinciri paradigmasını biçimlendirmek için karbon sınır politikası, çevresel kısıtlamalar açısından karbon emisyonlarını kontrol etmek için benimsenmiştir. Ayrıca, önerilen modelin izlenebilir karşılığı, dağılımsal olarak sağlam güvenilirlik hedefi ve kısıtlamaların belirsiz parametrenin belirsiz dağılımı altında eşdeğer formlarına dönüştürülmesiyle elde edilmiştir. Önerilen modelin avantaj1, dağıtım belirsizliği içermeyen ve çevresel kısıtlama sorunu olmayan karşılaştırmalı çalışma ile gösterilmiştir.

\section{Materyal ve Metot}

\subsection{Electre I Metodolojisi}

Adım 1:Öncelikle karar matrisi (A) oluşturulmaktadır. Karar matrisinin satırlarında üstünlükler açısından sıralanması istenen alternatifler, sütunlarında ise karar vermede kullanılması istenen değerlendirme faktörleri bulunmaktadır. A matrisi karar verici tarafından oluşturulan başlangıç matrisidir.

Adım 2:Normalize karar matrisi (X) oluşturulmaktadır. Maliyet ve fayda kriterleri için farklı formüller kullanılmaktadır.

Adım 3:Ağırlıklandırılmışnormalize matris elde edilmektedir. Karar verici öncelikle değerlendirme faktörlerinin ağırlıklarını $\mathrm{W}_{\mathrm{j}}$ olarak belirlemelidir. $\sum_{\mathrm{i}=1}^{\mathrm{n}} \mathrm{W}_{\mathrm{j}}=1$ eşitliği dikkate alınır. Normalize edilmiş matris kriterlerin ağırlıklarıyla çarpılarak ağırlıklandırılmış normalize matris elde edilmektedir.

Adım 4:Uyum ve uyumsuzluk kümelerinin oluşturulması gerekmektedir. Uyum ve uyumsuzluk kümeleri oluşturulur. Her ikili alternatif karşılaştırılması için kriterler iki farklı kümeyeayrılır. Ap ve Aq $(1,2, \ldots, m$ ve $p \neq q)$ uyum kümesinde AP alternatifi Aq'ya tercih edilmektedir. AP eğer Aq'dan daha kötü bir alternatif ise uyumsuzluk kümesi oluşturulur.

Adım 5:Uyum ve uyumsuzluk indeksleri hesaplanmaktadır. Uyum matrisinin (C) oluşturulması için uyum setlerinden yararlanılır. Uyum kümesi $\mathrm{C}(\mathrm{p}, \mathrm{q})$ 'da yer alan faktörlerdir. Uyumsuzluk matrisinin (D) elemanları ise aşağıdaki formül yardımıyla hesaplanır. Uyumsuzluk kümesi $\mathrm{D}(\mathrm{p}, \mathrm{q})$ 'da yer alan faktörlerdir.

Adım 6:Üstünlük karşılaştırılması yapılmaktadır. C $\quad$ v $\quad$ D değerlerinin ortalamaları $\mathrm{C}^{*}$ ve $\mathrm{D}^{*}$ değerleri olarak hesaplanır. Eğer $C_{p q} \geq C^{*}$ ve $D_{p q} \leq D^{*}$ ise $A P \rightarrow$ Aq'dir. Yani $p$ birim $q$ birime göre üstündür denilebilir.

Adım 7:Son olarak net uyum ve uyumsuzluk indeksleri hesaplanmaktadır. $C_{p}$ 'ler büyükten küçüğe $D_{p}$ 'ler küçükten büyüğe sıralanır. Böylece sıralama elde edilmiş olur. 


\section{Otomotiv Sektöründe Faaliyet Gösteren Tedarikçi Adayları ile Tedarikçi Seçimi Uygulaması}

\subsection{Yeşil Tedarik Zinciri Kriterinin Anket Yöntemi ile Oluşturulması}

Bilimsel araştırmaların kalitesi, büyük oranda kullanılan yöntemin tutarlılığına bağlıdır. Bu çalışmanın uygulama alanı ve sonuçlarının daha tutarlı ve gerçekçi olabilmesi için 5 sorudan oluşan bir anket 3 farklı tedarikçinin lojistik ve yeşil lojistik uygulamalarında uzman onbeş kişiye ulaştırılmıştır. Uzmanlardan aşağıda Tablo 5 olarak verilmiş soruları 1'den 5'e kadar puanlamaları istenmektedir.

Değerlendirme ölçütleri ilk 4 soru için aşağıdaki Tablo 2 'de verilmiştir. Son soru için değerlendirme ölçütü puan cinsinden Tablo 3 'te verilmiştir. Tüm bu bilgiler ışığında; uzman ekiplerin her bir soruya vermiş olduğu cevaplar her bir tedarikçi için analiz edilmiştir. Her bir soru için belirlenmiş ortalama değerler her bir sorunun tedarikçi yeşil lojistik değeri için aynı ağırlıkta olduğu farz edilerek tekrar aritmetik ortalama hesaplamasına tabii olmuştur. Tablo 4'te nihai yeşil lojistik değerleri tedarikçi bazında paylaşılmıştır.

Tablo 2. Yeşil tedarikçi seçimi için yeşil lojistik kriterleri anket sorularl- Değerlendirme Ölçütü

\begin{tabular}{|l|l|}
\hline Puan & Değerlendirme Ölçütü \\
\hline 1 & Hiçbir zaman \\
\hline 2 & Nadiren \\
\hline 3 & Genellikle \\
\hline 4 & Sik sık \\
\hline 5 & Her zaman \\
\hline
\end{tabular}

Tablo 3. Yeşil tedarikçi seçimi için yeşil lojistik kriterleri anket sorulart- Son Süreç Tanımı

\begin{tabular}{|l|l|}
\hline Puan & Son Süreç Tanımı \\
\hline 1 & Gömme \\
\hline 2 & Geri dönüştürme \\
\hline 3 & Yeniden üretme \\
\hline 4 & Yeniden kullanma \\
\hline 5 & Bertaraf etme \\
\hline
\end{tabular}

Tablo 4. Tedarikçi özelinde yeşil lojistik değerlendirme sonuçları

\begin{tabular}{|l|l|}
\cline { 2 - 2 } \multicolumn{1}{c|}{} & Yeşil Lojistik Değerlendirme Sonuçları \\
\hline Tedarikçi 1 & 3,26 \\
\hline Tedarikçi 2 & 2,95 \\
\hline Tedarikçi 3 & 3,94 \\
\hline
\end{tabular}

Tablo 5. Yeşil tedarikçi seçimi için yeşil lojistik kriterleri anket soruları

\begin{tabular}{|c|c|}
\hline Anket soruları & Puan \\
\hline $\begin{array}{l}\text { Soru 1: Sizde ve alt tedarikçilerinizde üretim esnasında oluşan atıkları geri topluyor ve yeniden } \\
\text { kazandırıyor musunuz? }\end{array}$ & \\
\hline $\begin{array}{l}\text { Soru 2: Paketleme sisteminiz yeşil paketlemeye (birden çok kullanım, doğa dostu paketler vs) } \\
\text { uygun mudur? }\end{array}$ & \\
\hline $\begin{array}{l}\text { Soru 3: Yeşil dağıtım kriterlerine uygun çalışıyor musunuz? (Tekrar tekrar kullanılabilen } \\
\text { dağıtım gereçleri, kasalar, konteynrlar vs.) }\end{array}$ & \\
\hline $\begin{array}{l}\text { Soru 4: Alt tedarikçilerinizin size parça temin ettikleri noktalarda geri çağırma stratejisinde } \\
\text { tersine tedarik zinciri oluşturuyor musunuz? }\end{array}$ & \\
\hline $\begin{array}{l}\text { Soru 5: Tersine lojistik ağınızı son halkası aşağıdakilerden hangisidir? } \\
\text {-Gömme } \\
\text {-Geridönüştürme } \\
\text {-Yenidenüretme } \\
\text {-Yenidenkullanma } \\
\text {-Bertaraf etme }\end{array}$ & \\
\hline
\end{tabular}

Tablo 6: Kriter son ăgırlık matrisi

\begin{tabular}{|l|l|l|l|l|l|l|l|}
\hline & & $\begin{array}{l}\text { Karar } \\
\text { Verici 1 }\end{array}$ & $\begin{array}{l}\text { Karar } \\
\text { Verici 2 }\end{array}$ & $\begin{array}{l}\text { Karar } \\
\text { Verici 3 }\end{array}$ & $\begin{array}{l}\text { Karar } \\
\text { Verici 4 }\end{array}$ & $\begin{array}{l}\text { Kriter Ă̆ırlık } \\
\text { Ortalaması }\end{array}$ & $\begin{array}{l}\text { Ağırlıklı Kriter } \\
\text { Sıralama }\end{array}$ \\
\hline Kriter 1 & Kalite & 0,269 & 0,141 & 0,179 & 0,165 & 0,188 & 4 \\
\hline Kriter 2 & Maliyet & 0,306 & 0,221 & 0,156 & 0,218 & 0,225 & 1 \\
\hline Kriter 3 & Mühendislik & 0,129 & 0,298 & 0,282 & 0,157 & 0,216 & 2 \\
\hline Kriter 4 & Yeşil Lojistik & 0,174 & 0,148 & 0,268 & 0,189 & 0,195 & 3 \\
\hline Kriter 5 & Yönetim & 0,123 & 0,192 & 0,115 & 0,272 & 0,175 & 5 \\
\hline
\end{tabular}




\subsection{Kriterlerin Ağırlıklandırılması}

Araştırma kapsamında yapılan bu çalışmada, SWARA (StepwiseWeightAssessmentRatio Analysis- Kademeli AğırlıkDeğerlendirme Oran Analizi) ile belirlenen kriterlerin uzman kişiler tarafından ne ölçek ile ağırlıklandırıldığı incelenmiştir. SWARA yöntemi, karar vericiye önceliklerini seçme olanağı veren uzman odaklı bir yöntem olarak görülmektedir. $\mathrm{Bu}$ yöntemin temel özelliği, kriter ağırlıklarının belirlenmesi adımında kriterlerin önem oranlarına bağlı uzman görüşlerini tahmin edebilme yeteneğidir.

$\mathrm{Bu}$ çalışmada; uzman yetkinliğine sahip kara vericilere belirlenen 5 kriter arasından önem düzeyi en yüksek olandan başlayarak en düşük olana doğru sıralama yapması istenmiştir. Her bir karar vericinin sıralı önem dereceleri saptanmıştır. Tablo 'da karar verici 1'e ait önem sırası listesi verilmiştir.5 farklı karar vericinin önem sırası uzman görüşleri için SWARA yöntemi uygulanmıştır. Tüm karar vericilerin görüşlerini içeren kriter son ağılık matrisleri oluşturulur. Tablo 6'de uygulama için hesaplanmış kriter son ağırlık matrisi verilmiştir.

\section{ELECTRE I Uygulanmasının Sonuçları ve Tartışma}

İzlenecek adımlar şu şekildedir;

Birinci adım olarak; toplam karar matrisi oluşturulur.

Tablo 7. Toplam karar matrisi

\begin{tabular}{|l|l|l|l|l|l|}
\hline & K1 & $\mathbf{K ~ 2}$ & $\mathbf{K 3}$ & $\mathbf{K 4}$ & $\mathbf{K 5}$ \\
\hline & Kalite & Maliyet & Mühendislik & $\begin{array}{l}\text { Yeşil } \\
\text { Lojistik }\end{array}$ & Yönetim \\
\hline W & $\mathbf{0 , 1 8 8}$ & $\mathbf{0 , 2 2 5}$ & $\mathbf{0 , 2 1 6}$ & $\mathbf{0 , 1 9 5}$ & $\mathbf{0 , 1 7 5}$ \\
\hline T1 & 4,68 & 4,21 & 3,68 & 3,26 & 3,33 \\
\hline T2 & 3,29 & 3,89 & 4,22 & 2,95 & 4,31 \\
\hline T3 & 3,24 & 3,52 & 3,46 & 3,94 & 4,95 \\
\hline
\end{tabular}

İkinci ve üçüncü adım olarak; standard karar matrisi ve ardından ağırlıklandırılmışstandard karar matrisi oluşturulur.

Tablo 8. A $\breve{g l} ı l l k l$ standard karar matrisi

\begin{tabular}{|l|l|l|l|l|l|}
\hline & K1 & K2 & K3 & K4 & K5 \\
\hline & Kalite & Maliyet & Mühendislik & $\begin{array}{l}\text { Yeşil } \\
\text { Lojistik }\end{array}$ & Yönetim \\
\hline W & 0,188 & 0,224 & 0,216 & 0,194 & 0,175 \\
\hline T1 & 0,134 & 0,060 & 0,120 & 0,107 & 0,079 \\
\hline T2 & 0,094 & 0,065 & 0,138 & 0,097 & 0,102 \\
\hline T3 & 0,092 & 0,060 & 0,099 & 0,125 & 0,126 \\
\hline
\end{tabular}

\section{Sonuç}

Endüstrinin sürekli gelişimi ciddi çevresel zararlara neden olmuş ve bu nedenle çevre koruma kavramı tedarik zincirine dahil edilmiş ve böyleceolağanüstü çevresel başarı eldeedilmiştir
Dördüncü adım olarak; Tablo 9'da her bir sete ait hesaplanmış uyum ve uyumsuzluk katsayıları belirtilmiştir. $\mathrm{Bu}$ değerler doğrultusunda setlerin uyum matrisleri ve uyumsuzluk matrisleri hazırlanır.

Tablo 9. Uyum ve uyumsuzluk setleri

\begin{tabular}{|l|l|l|l|}
\hline & Uyum seti & & Uyumsuzluk seti \\
\hline C12 & 1,4 & D12 & $2,3,5$ \\
\hline C13 & 1,3 & D13 & $2,4,5$ \\
\hline C21 & $2,3,5$ & D21 & $1,4,2$ \\
\hline C23 & 1,3, & D23 & 4,5 \\
\hline C31 & $2,4,5$ & D31 & 1,3 \\
\hline C32 & $2,4,5$ & D32 & 1,3 \\
\hline
\end{tabular}

Beşinci adım; uyum ve uyumsuzluk katsayılarının hesaplanmasidır.

Tablo 10. Uyum ve uyumsuzluk katsayıları

\begin{tabular}{|l|l|l|}
\hline & Uyum katsayısı & Uyumsuzluk katsayısı \\
\hline C12/ D12 & 0,383 & 0,58 \\
\hline C13/ D13 & 0,405 & 1,00 \\
\hline C21/ D21 & 0,617 & 1,00 \\
\hline C23/ D23 & 0,405 & 0,71 \\
\hline C31/ D31 & 0,595 & 0,94 \\
\hline C32/ D32 & 0,595 & 0,87 \\
\hline
\end{tabular}

Altıncı adım olarak; uyum ve uyumsuzluk katsayıları kullanılarak sirasıyla uyum matrisleri ve uyumsuzluk matrisleri oluşturulur. $\mathrm{Bu}$ matrisler ışığında; sırasıyla uyum üstünlük matrisleri ve uyumsuzluk üstünlük matrisleri oluşturulur. Son adım olarak tablo 11 'de gösterildiği gibi toplam baskınlık matrisi oluşturulur.

Tablo 11. Toplam Baskınlık Matrisi

\begin{tabular}{|l|l|l|l|}
\hline & T1 & T2 & T3 \\
\hline T1 & - & 0,000 & 0,000 \\
\hline T2 & 1,000 & - & 0,000 \\
\hline T3 & 1,000 & 1,000 & - \\
\hline
\end{tabular}

Yapılan çalışmada ile otomotiv sektöründe faaliyet gösteren 3 farklı tedarikçinin performans değerlendirme sonuçları 1şığında en etkin tedarikçileri sıralamak amaçlanmıştır. 5 farklı kriter ile tedarikçi seçimi problemine çözümler aranmış ve ÇKKV yöntemi uygulaması yapılmıştır. Bu kriterler özelinde, uzman görüşleri dikkatle incelenmiş ve analizler yapılarak çalışmaya girdi oluşturulmuştur.

Yeşil inşaat tedarik zinciri, özellikle inşaat tedarik zincirinde tedarik zinciri temelleriyle ilgili olarak son zamanlarda tartışılan konulardan biri olup, yeşil satın alma, yeşil nakliye ve dağıtım, yeşil üretim ve yeşil inşaat faaliyetleri ve ürünlerin kullanım ömrü sonu yönetimi gibi çeşitli sürdürülebilir uygulamaları kullanarak çevresel sürdürülebilirliği geliştirme yönünde tedarik 427 
zinciri yönetiminde kapsamında kullanılan bir unsurdur. İşletmelerin çoğu, dünyanın çevresel olarak sürdürülebilir kalkınmasını sağlamak için tedarik zincirinde yeşil uygulamaları

Yapılan çalışmada ile otomotiv sektöründe faaliyet gösteren 3 farklı tedarikçinin performans değerlendirme sonuçları 1şığında en etkin tedarikçileri sıralamak amaçlanmıştır. 5 farklı kriter ile tedarikçi seçimi problemine çözümler aranmış ve ÇKKV yöntemi uygulaması yapılmıştır. Bu kriterler; kalite, mühendislik, yeşil lojistik, maliyet ve yönetim olarak belirtilmiştir. Her bir kriter için farklı uzmanlara anketler yapılmış ve görüşleri tedarikçi karşılaştırma olarak alınmıştır. Yeşil lojistik kriterine ait anketler paylaşılmış. Yeşil lojistik araştırmaları ve çalışmalarına 1 şı tutması özellikle amaçlanmıştır. SWARA yöntemi kullanılmış ve notasyonları paylaşılmıştır. $\mathrm{Bu}$ tedarikçi seçimi problemi ELECTRE I uygulaması sonucunda; Tedarikçi 1'in hiçbir tedarikçiye baskın olmadığı, Tedarikçi 2'nin Tedarikçi 1'e baskın olduğu, Tedarikçi 3'ün ise hem Tedarikçi 1 hem de Tedarikçi 2'ye baskın olduğu saptanmıştır.

Çalışmanın amacı, ÇKKV yöntemi olan Electre yöntemi ile otomotiv endüstrisinde faaliyet gösteren 3 farklı tedarikçiye yönelik performans değerlendirme sonuçlarına bağlı olarak en etkin tedarikçileri sıralamasının belirlenmesidir. Belirlenen 5 farklı kritere yönelik tedarikçi seçimi probleminin çözümü ve ÇKKV yöntemi uygulaması gerçekleştirmiştir. Belirlenen bu kriterler; kalite, mühendislik, yeşil lojistik, maliyet ve yönetim olarak tespit edilmiştir. Tedarikçi seçimi problemi ELECTRE I uygulamasının sonucuna bağlı olarak Tedarikçi 1'in hiçbir tedarikçiye üstünlüğü olmadı̆̆ı, Tedarikçi 2'nin Tedarikçi 1'e göre üstün olduğu, Tedarikçi 3'ün ise hem Tedarikçi 1 hem de Tedarikçi 2'ye üstün olduğu-baskın olduğu tespit edilmiş, anlaşılmıştır.

Yapılan araştırma sayesinde ELECTRE metodu kullanılarak karar verici ve araştırmacıların çok sayıda farklı nicel ve nitelikteki kriterleri, ölçütleri karar verme sürecine dahil edebilmektedir. Buna bağlı olarak belirlenen ölçütleri-kriterleri belirlenen hedefler doğrultusunda ağırlıklandırabildikleri ve ağırlıklar kapsamında en uygun seçeneği-alternatifi rahatlıkla tespit edebilmeleri sunulmuştur.

\section{Teşekkür}

Değerli bilgilerini bizim ile paylaşanve çalışma kapsamımızda anket çalışmamıza katılarak katkı saylayan işletmeyetkililerine, otomotiv sanayii çalışanlarına ve satın alma uzmanlarına teşekkür ederiz.

\section{Kaynakça}

Akpınar, N. (2003). Sürdürülebilir alan kullanım planlamasında alan kullanım tiplerine ait önceliklerin Simos Prosedürü ve ELECTRE 1 yöntemi ile belirlenmesi. Tarım Bilimleri Dergisi, 9(2), .234-242.

Akyüz, Y. ve Soba, M. (2013). Electre yöntemiyle tekstil sektöründe optimal kuruluş yeri seçimi: Uşak ili örneği. Uluslararası Yönetim İktisat ve İşletme Dergisi, 9(19), 185 198.

e-ISSN: $2148-2683$
Atıc1, K. ve Ulucan, A. (2009). Enerji projelerinin değerlendirilmesi sürecinde çok kriterli karar verme yaklaşımları ve Türkiye uygulamaları. Hacettepe Üniversitesi İktisadi ve İdari Bilimler Fakültesi Dergisi, 27 (1), 161-186

Bai, C. ve Sarkis, J. (2010). "Green Supplier Development: Analytical Evaluation Using Rough Set Theory", Journal of Cleaner Production, 18(12), 1200-1210.

Blome, C., Hollos, D. ve Paulraj, A. (2014). “Green Procurement and Green Supplier Development: Antecedents and Effects On Supplier Performance", International Journal of Production Research, 52(1), 32-49.

Büyüközkan ve Çiftçi (2012),A novel hybrid MCDM approach based on fuzzy DEMATEL, fuzzy ANP and fuzzy TOPSIS to evaluate green suppliers, Expert Systems with Applications 39(3), 3000-3011.

Çağıl, G. (2011). 2008 Küresel kriz sürecinde Türk bankacılık sektörünün finansal performansının ELECTRE yönetimi ile analizi, Maliye ve Finans Yazıları, 1 (93), 59-86.

Christian N. C. (2007). Environmental Planning and Management, Singapore, Imperial College Press.

Curkovic, S., Sroufe, R. ve Melnyk, S. (2005). Identifying the Factors Which Affect the Decision to Attain ISO 14000, Energy, 30, 1387-1407.

Dou, Y., Zhu, Q. ve Sarkis, J. (2014), "Evaluating Green Supplier Development Programs With A Grey-Analytical Network Process-Based Methodology", European Journal of Operational Research, 233(2), 420-431.

Ertuğrul, İ. ve Karakaşoğlu, N. (2011). ELECTRE ve bulanık AHP yöntemleri ile bir işletme için bilgisayar seçimi. Dokuz Eylül Üniversitesi İktisadi ve İdari Bilimler Fakülte Dergisi, 25(2), 23-41.

Eryürek, Ö. F. ve Tanyaş, M. (2003). Hata türü ve etkileri analizi yönteminde maliyet odaklı yeni bir karar verme yaklaşımı. İTÜ İşletme Fakültesi, Endüstri Mühendisliği Bölümü Dergisi, 31-40.

Fu, X., Zhu, Q. ve Sarkis, J. (2012), “Evaluating Green Supplier Development Programs At A TelecommunicationsSystems Provider", International Journal of Production Economics, 40, 357-367.

Govindan, K., Kaliyana, M., Kannan, D. ve Haq, A.N. (2014). Barriers Analysis for Green supply chain management implementation in Indian industries using analytic Hierarchy process, International Journal of Production Economics 147, Part B, 555-568.

Humphreys, P., Matthews, J. And Kumaraswamy, M. (2003). Pre-construction Project partnering: From adversarial to collaborative relationships, Supply Chain Management 8(2), 166-178.

Karacasu, M. (2007). Kent içi toplu taşıma yatırımlarının değerlendirilmesinde karar destek modeli (ELECTRE Yöntemi) kullanımı. 7. Ulaştırma Kongresi, İstanbul.

Lamba, N. ve Thareja, P. (2020). Developing the structural model based on analyzing the relationship between the barriers of Green supply chain management using TOPSIS approach. Materials Today: Proceedings.

Li, Y.-H. ve Huang, J.-W. (2017). Themoderating role of relational bonding in green supply chain practices and performance. Journal of Purchasing and Supply Management, 23(4), 290-299.

Liu, Y., Ma, L., ve Liu, Y. (2020). A novelrobustfuzzymeanUPM model for gren closed-loop supply chain network 
design under distribution ambiguity. Applied Mathematical Modelling, 92, 99-135.

Luitzen de, B. ve Eva, L.(2001), A review of methods supporting supplier selection, European Journal of Purchasing and Supply Management, 7, 75-89.

Mojumder, A. ve Singh, A. (2021). An exploratorystudy of theadaptation of Green Supply Chain Management in Construction Industry: the case of Indian Construction Companies, Journal of Cleaner Production, 126, 400.

Reza Hoseini, A.,Noori, S. ve Ghannadpour, S.F. (2021). Integrated scheduling of suppliers and multi-project activities for Green construction supply chains under uncertainty, Automation in Construction, 122, February 2021, 103485.

Soner, S. ve Önüt, S. (2006). Çok kriterli tedarik seçimi: bir ELECTRE - AHP uygulaması. Sigma: Mühendislik ve Fen Bilimleri Dergisi, 110-120.

Tunçel, N., Belbağ, S. ve Çimen, M., (2017), Satın alma kriterleri açısından marka sıralama kararının verilmesinde bulanık Electre I yöntemi: Otomobil sektöründe bir uygulama. Atatürk Üniversitesi İktisadi ve İdari Bilimler Dergisi, 31 (5), 1069-1085.

Türker, A. (1988). Çok ölçekli karar verme tekniklerinden ELECTRE. İstanbul Üniversitesi Orman Fakültesi Dergisi, 38(3), 72-87.

Ulucan A, ve Atıc1 K. (2009). Enerji projelerinin değerlendirilmesi sürecinde çok kriterli karar verme yaklaşımları ve Türkiye uygulamaları. H.Ü. İktisadi ve İdari Bilimler Fakültesi Dergisi, 27(1), 161-186

Yürekli, H. (2008). Taarruz helikopterleri seçiminde ELECTRE yönteminin kullanılması. (Doktora Tezi). İstanbul Üniversitesi Sosyal Bilimler Enstitüsü İşletme Anabilim Dalı Sayısal Yöntemler Bilim Dalı, İstanbul.

Wang, C., Zhang, Q. ve Zhang, W. (2020). Corporate social responsibility, Green supply chain management and firm performance: The moderating role of big-data analytics capability. Research in Transportation Business \& Management, 100557.

Zeger D., Eva, L. ve Filip, R.,(1999). An evaluation of vendor selection models from a total cost of owner shipperspective, European Journal of Operational Research, 125, 34-58.

Zaid, A. A., Jaaron, A. A. M. ve Talib Bon, A. (2018). The impact of green human resource management and green supply chain management practices on sustainable performance: An empirical study. Journal of Cleaner Production, 1-51 